\title{
PARANOID SCHIZOPHRENIA AND THE PARADOXICAL PATH TO PARAPHRENIA AND AFFECTIVITY - A CASE STUDY
}

\author{
Tiana Voicu ${ }^{*}{ }^{\natural}$, Ana Maria Chipeșiu ${ }^{2}$, Simona Trifu ${ }^{3}$ \\ ${ }^{* 1,2} 2$ University of Bucharest Faculty of Psychology and Educational Sciences, Department of \\ Psychology (ROMANIA) \\ 3 "Carol Davila" University of Medicine and Pharmacy, Department of Neurosciences (ROMANIA)
}

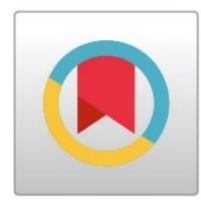

DOI: https://doi.org/10.29121/granthaalayah.v8.i5.2020.71

Article Type: Case Study

Article Citation: Tiana Voicu, Ana Maria Chipeșiu, and Simona Trifu. (2020). PARANOID SCHIZOPHRENIA AND THE PARADOXICAL PATH TO PARAPHRENIA AND AFFECTIVITY A CASE STUDY. International Journal of Research GRANTHAALAYAH, 8(5), 15-21. https://doi.org/10.29121/granthaa layah.v8.i5.2020.71

Received Date: 12 May 2020

Accepted Date: 22 May 2020

\section{Keywords:}

Paranoid Schizophrenia

Dissociation

Affectivity

Insight

Delusional Ideas of Greatness and Persecution

Paraphrening State

\section{ABSTRACT}

Motivation: Analyzing a case of paranoid schizophrenia is a challenge to understand the mechanisms underlying the mind of a schizophrenic. The study became captivating because in the patient's delusional cofabulations there were many fingerprints that the communist period of that time left on the woman's psyche, thus observing the repressions following personal failures that probably led to the current state.

Objective: Carrying out an analysis of the life history of a patient with paranoid schizophrenia who, although voluntarily presenting at the hospital, does not recognize her diagnosis and treatment. It presents symptoms that include the delusional ideas of persecution or greatness. It has two possible admissions, currently admitted to the psychiatric department in Bucharest.

Results: The patient presents disorders regarding perception, memory, affectivity, observing a disorganized discourse that includes a qualitative perceptual disorder, schizophrenia-specific hypoprosexias, disorders of the immediate mental synthesis with illusions of nonrecognition, impossibility of evoking recent events, mental and ideation disorganization, the reversal of the affective, which generates conflicting emotional experiences.

Conclusion: Although the patient is under treatment, insight is still not present, so patient supervision is recommended. The paranoid nucleus has diminished, but delusional ideas still persist, and the patient became affected during hospitalization.

\section{INTRODUCTION}

\subsection{GENERAL DESCRIPTION OF THE CASE}

\section{Personal Data}

- The patient is 56 years old at the current hospitalization;

- Born in country side, Romania;

- Born in a family with 5 members, the parents and 2 brothers;

- $\quad$ Mother - deceased in 2008; the cause is unknown;

(C) 2020 The Author(s). This is an open access article distributed under the terms of the Creative Commons Attribution License, which permits unrestricted use, distribution, and reproduction in any medium, provided the original author and source are credited. 
- The father - deceased in 1992;

- Brothers - still alive; one of them lives at the patient's home with her daughter;

- Divorced in 2001;

- She has a daughter born in 1987;

- She might have lost a pregnancy after her first child.

\section{Studies}

- Attended general school;

- Finished a high school with a humanistic profile in Bucharest, until around 1974-1975; took the baccalaureate exam a year later;

- 1976 - states that she started her studies at the Faculty of Foreign Languages at the University of Bucharest

- 1976 - 1977 - due to the lack of possibility to continue the studies at the university, he was employed with a workbook on the position of technical designer until 2012;

- The patient claims that she also attended the courses of the "Carol Davila" Faculty of Medicine and Pharmacy in Bucharest, but we do not know the truthfulness of this information;

- During the higher level studies, the patient attended different student manifestations specific to the communist period, such as hunger strikes; these events could have had a major impact on her and the further development of psychiatric symptomatology;

- The patient may not have completed any form of higher education.

\section{Forensic History}

- The apparent onset of the disease can be located in the post-adolescence period, in the 12th grade; the triggering event of the patient's disorder is a possible school failure, materialized in the repetition of a high school year, which affected its further development on a professional and personal level;

- A first significant episode is a meeting with a colleague who asked her to help her leave the country. The patient states that she accompanied her colleague in an interview with Mrs. Elena Ceaușescu. It is possible that certain circumstances in which she tried to help her colleague to leave the country have led her to develop delusional ideas of persecution, which have as main theme the social influence of the Ceausescu family;

- Possibly the first hospitalization took place when she received the first diagnosis in adulthood, which led to the woman's retirement due to illness;

- The possible missed pregnancy mentioned above may be the triggering event for the severe mental degradation of the patient, which led to the deterioration of the relationships with the nucleus family;

- Interned at the psychiatry department in Brașov, after being found on the platform of the train station, addressing the insults of the passers-by and having an aggressive behavior; the patient does not remember the admission from Brasov;

- 2010 - another hospitalization at the psychiatry department;

- 2011 - social investigation at home while hospitalized in Brasov;

- Currently hospitalized for the fourth time; does not yet accept the diagnosis.

\section{About Her Family}

- The family consists of "drunkards, intellectuals, with different lives"

- The members of the family are "reluctant and ignorant"; they call them "Angalați" - "reluctant; individuals who do not know how to write"

- The two brothers are considered "impostors"; "I discovered this by doing research"

- "I have a twin sister who was admitted; what I was doing was actually my sister through me" 
- $\quad$ "My husband must remain secret because he is a public person" - the imaginary husband

- She states very little about her former husband, whom she does not always recognize in her speech.

\section{Current Speech}

Regarding the birth of the child or the potential abortion:

- "It would have been better to birth alone"

- "They took me to a hospital of angalați"

- "I was operated by a butcher who cursed me for three days"

- "I had a child whom name was Chocolate"

- "I call him Chocolate because he liked chocolate and he smiled when I called him like that"

- "I spoke to the child in English and Romanian, and the baker was outraged"

- "I have a child who has lived but is not declared"

- $\quad$ I was talking in the subconscious with my child

\section{Family}

- "I was adopted by Bush"

- "My natural father died from a terrorist attack"

- Relations with partners:

- $\quad$ "I divorced in 2001";

- "My husband is Richard Chamberlain";

- "I lived with a man sick with rabies";

- "My husband made me an artist"

- "I was attacked by a homosexual"

\section{Dissociation:}

- "My sister was admitted several times"

- " "I suffered because of her"

- "I was bullied to be a babysitter"

- "I was controlled by my twin sister"

\section{Ideas of greatness and persecution}

- "I have a lot of Oscars"

- "I was the slave of the Ceausescu clan"

- "I had a head surgery and a paid killer hit me with the hammer in the head"

\section{Hallucinations}

- "The voices are not heard in the head, but in the soul"

- "No voices can be heard in the head, because there is only gelatinous matter "

- "I didn't hear voices in my ears because I was an artist and I only wore earphones"

\subsection{HOSPITALIZATION IN A PSYCHIATRIC HOSPITAL}

- $\quad 90$ s - Possible two previous hospitalizations, in the adult period

- 2010 - Admission to the psychiatry department in Brasov

- Present - She is admitted to the psychiatry department in Bucharest for 5 weeks, with a diagnosis of schizophrenia-paranoid, having a systematic delirium based on ideas of greatness and persecution. 


\subsection{CURRENT EPISODE}

The patient recounts a life history full of traumatic events, especially because she lived in a period when Romania was ruled by a communist regime. All the shortcomings and the lack of achievements in line with the big expectations of the schooling period made her vulnerable and led to the repression of these incidents in the unconscious. The failed marriage and the possible story of an abortion led her to resort to delusional confabulations, as the mechanisms of repression did not help her anymore [1]. The patient is quite affected when she tells the story of that ghostly baby "Chocolate", as she calls it, because she states that the baby liked chocolate even before birth. The same can be said about her educational and professional career, which she probably did not live up to as she wished. The multitude of professions she claims to have had, including that of a doctor, shows her regrets due to unfulfilled intellectual aspirations, which led to her inner degradation and possible split of the self. In the same idea also appear her intellectual knowledge and the foreign languages (Arabic, Turkish, English) that she apparently knows. All things have arised in the attempt to rationalize and explain some personal information and events. The association with proeminent personalities of the time, such as Bush, denotes her attempt to make up for the lack of fulfillment and explains the emergence of persistent delusional ideas of greatness and filiation. The delusional idea that she is adopted and her inability to accept her family suggests a broken relationship with her peers, which she probably did not feel at her side during difficult times. Also, the presence of alcoholism in the patient's reports about her family of origin may explain her desire to overcome this precarious living condition or a possible projection of her own addiction, as a way to compensate for the deficits [2] [3].

\section{MATERIALS AND METHODS}

In the 5 weeks of current hospitalization, the patient received a treatment that led her to affectivity, but delusional ideas still persist. She has been examined from the psychological point of view and of the physical and social functionality, of the discernment, and at the same time her medical evolution is being followed.

\section{RESULTS AND DISCUSSIONS}

\subsection{EXAMINATION OF THE PRESENT MENTAL STATE}

Observations: The patient is florid, presents a wide range of delusional polymorphic ideas, of greatness and persecution, with the advent of intellectualization in the speech and conveys certain emotions through the way she talks about her past. She has a tendency to dissociate from traumatic experience, and the tendency becomes obvious by the construction of his twin sister; the disorder has not been remitted to date.

Perception: A qualitative perceptive disorder is present. The patient recalls that she was talking subconsciously to her child (the phantasm child, the result of her projection), but says that "Voices are not heard in the head, but in the soul." Thus, these are interoceptive pseudohalucinations, which not mentioned in the present by the patient. She believes that no voices can be heard in the head, because there is only "gelatinous matter". She also denies hearing "voices in her ears", but recalls that she always had headphones in her ears, being "artist". Auditory and visual hallucinations were recorded in the medical records at the time of admission, but are not remembered or detailed by the patient during the interview.

Attention: There are no persistent disorders, but there may be the schizophrenia-specific hypoprosexuals, with particular character through difficult to explain motivational changes. Relatively indistinguishable disturbances in the attention may have affected the patient's social functioning, especially educationally and professionally. They can thus constitute adverse effects of schizophrenia disorder, where there is often a lack of concentration power on activities. Although the patient denies a deficient educational path, it is likely that the impairment of prosexic function has led to the impediment to her functional development.

Memory: Disorders of immediate mnestic synthesis appear, where non-recognition illusions occur ("They are not my brothers"). The patient exhibits a possible fixing amnesia that disrupts thinking. They lead to an impossibility of evoking recent events, but as noted in her speech, the memories set are well preserved, although placement in time and space is flawed. Moreover, hypermnesia occurs at the quantitative level for dates, years, human names ("I worked with the workbook from October 4, 1976 to 2012"; "I divorced in 2001"). It also presents reduplication

International Journal of Research -GRANTHAALAYAH 
paramnesia, which means that all important people are duplicated in order not to lose them. So there are biological parents in association with the adoptive ones ("I was adopted by Bush") the phantasm child (states that she had a child who liked chocolate very much as a child, which she lost and with whom maintains a communication at the subconscious level) in association with the biological daughter.

Thinking: Word buildings are observed, such as the word "Angalaţi", which symbolizes "undetermined individuals, who do not know how to write" to her. This word often appears used in her disorganized speech and relates to her place of origin, where she spent much of his time. The mental disorganization and the idealistic plan are highlighted by the multitude of events reported in the interview and correlate with tangential responses, the circumstantiality of the speech. When asked about her diagnosis, she insists it is a false diagnosis, and in the end she does not name it and avoids talking about it. Moreover, she denies being her diagnosis, but her twin sister, and there is a dissociation capacity. [4] The patient builds another personality of herself on an oniric level to adapt and cope with traumatic events ("My sister has been admitted several times"). There are present polymorphic delusional ideas, especially ideas of greatness ("I have many Oscars"), of persecution and injury ("My thoughts were listened to after I had head surgery"). All these delusional ideas have as central themes violence and sexuality. There are also delusional ideas of parentage, as the patient denies belonging to her family of origin and associates with prominent personalities of the time, saying she was adopted by Us President George W. Bush. Husband's identity is also replaced by other figure figure personality, Richard Chamberlain. His desire to acquire an important social status is also noted in the statement that the wedding to the actor in question took place in Madrid. Mental automatism is highlighted when she states that she was forced from the outside to do certain things by remote control ("I was controlled by my twin sister"). There is a weakening of logical associates, with the patient noting that during her time as a high school student she was also a third-year medical student, that she was raped by a homosexual and operated on at the birth of the child by a butcher.

Affectivity: There is a qualitative affective disorder that represents an inversation of affection, which generates conflicting emotional experiences in disagreement with the typical affections of standard personal relationships (love for parents is transformed in hate). [5] The diagnosis of schizophrenia explains this poor management of the affects. A specific example of the patient's speech may be the lack of acceptance of her family of origin and all the delusional ideas that they are impostors and liars. The woman's fierceness on her parents and the presence of attachment disorders in their relationship are observed. Following the 5 weeks of admission during which she received treatment, the patient has become affected (full of emotion). This becomes obvious in the way she conveys strong emotions about delusional ideas.

Instinctive life: The patient's degree of danger is low, as delirium is very rich. The more abundant psychotic symptomatology, the lower the possibility of retaliation by heteroaggressive or self-aggressive acts. Due to the present dissociation, unconscious pulsations are blocked. However, it is recommended to monitor the patient in the conditions of lack of insight into the disease.

Activity: Because the patient is hospitalized, her social interactions are deficient, and because of the disease it would be difficult for her to form new social connections. From her speech, the relationship with the core family is impaired and absent, and the disorders in the sphere of memory and thought further prevent her from resuming their interpersonal relationships. According to her claims, she did not receive hospital visits while her hospitalization.

Disease consciousness: Absent

Current diagnosis: Paranoid schizophrenia [6]

\subsection{THE EVOLUTION DURING THE LAST HOSPITALIZATION}

The patient shows up at the hospital with symptoms from the paranoid nucleus. In the emergency room, the patient revealed auditory and visual hallucinations to the initial investigation and disorganization of thinking and memory disorders such as confessions. Auditory hallucinations are generally considered a psychiatric emergency, which involves supervision of the patient concerned. When admitted, the patient voluntarily presents herself and consents. However, it does not recognize diagnosis and treatment.

Based on the current psych examination, the patient's diagnosis is paranoid schizophrenia. Paranoid schizophrenia includes dominant symptoms like delusional ideas of persecution or greatness both present in the patient concerned. Auditory hallucinations that occur are related to the theme of delusional ideas that the patient 
accuses at the beginning of admission. As stated, the onset of this disorder occurs later than in other forms of schizophrenia, and the distinctive features persist for a longer period of time. [7] Thus, although the patient has been under treatment for at least 5 weeks, her symptoms continue to persist, with the lack of at least partial remission. Also, the patient was diagnosed during adult life, not during adolescence.

Currently, the patient is chronically ill with persistent thinking disorders. It has a disorganized delirium with hallucinations and auditory pseudohallucinations, with confabulations and pseudoreminescens. She is a florid in ideas and presents a phenomenon of mental transparency - she knows everything that is going in the external environment, but also others knows all about her. According to the criterion of evolution, the patient exhibits a continuity of symptoms after the onset of the disease. In the 5 weeks of current admission, the schizophren patient has become affectionate following the treatment and conveys strong emotions based on delusional ideas. Thus, the paranoid core has been reduced these weeks, under treatment, and the speech switches to the greatness side to compensate the absence of paranoia. She is more jovial so the current symptomatology disappears from the perceptive side to that of thought.

There is a paraphrenic tendency of the present condition of the patient, which involves a series of extremely rich chronic endogenous psychosis in terms of delirium, which disrupts good adaptation to the environment. [8] If the patient maintains a treatment rich in antipsychotics, she will tend to become flattened, developing a negative symptomatology. His protective barriers will be damaged in an attempt to cope with the disorder, and then she requires guidance and therapy to build a new functional world in line with external reality. The peculiarity of the case stems from the inability to remission, with continuous symptoms and a tendency to parafrenia, which no longer exists as the disease itself. It can be a more systematized, chronic delirium with hallucinations, as if living in a world of its own, from which it can easily break to carry out its daily activities, and then returns to her delirious world, as in the case of double countability of her own life.

Attention is also drawn to its marked dissociation capacity. From a psychodynamic perspective, dissociation appears as a defenment against the trauma suffered that is difficult to manage. Based on this action, we can say that the patient exhibits a pathological regression or reaches the height of non-differentiation, duplicity. She has fantastamatically constructed a twin sister to whom she attributes all the painful and traumatic events, even her own diagnosis, to cope with the present. The traumatic situations in the patient's life created a severe distress, which brought her to an area of mental exhaustion. [9] However, the patient does not appear to be dominated by the other fantasmatic personality, but only projects it outside. The power of non-differentiation as a mechanism is normal until the age of 5-6 years, especially for unhappy children, who form an identical self, with whom they no longer feel alone. [10]

\section{CONCLUSIONS AND RECOMMENDATIONS}

In conclusion, following the hospitalization of the patient diagnosed with paranoid schizophrenia, she has no awareness of the disease, although she is undergoing treatment for 5 weeks. Her condition was decompensated to an emotional side and a paraphrenic personality. This case study reveals an individualized prognosis of this disorder. However, the patient does not have a high degree of danger, because psychotic symptomatology is abundant thus reducing the risk of acts of aggression. Based on the patient's evolution over time, this case study has applicative relevance for psychiatric practice.

It is recommended to follow the patient's evolution and benefit from a therapeutic process of support and reintegration into the social world. Also, drug treatment should be counted, as the patient does not yet accept her diagnosis and may call into question the need for treatment. The current evolution of the condition, despite being under going on treatment for 5 weeks and lack of insight makes uncertain the formation of her ability to acquire criticism of the disease in the future. The patient is in a delicate position where interpersonal relations are affected, and due to the disorder she will find it difficult to link other social relationships in the future.

\section{SOURCES OF FUNDING}

None. 


\section{CONFLICT OF INTEREST}

None.

\section{ACKNOWLEDGMENT}

None.

\section{REFERENCES}

[1] Liebert, R. M., \& Spiegler, M. D. (1990). Personality: Strategies and Issues. California: Brooks - Cole Publishing Company.

[2] Trifu, S., Carp, E. G., \& Nadoleanu, A. (2017). Alcohol as A Substitute, Mask of Depression And "Antidote" Of Narcissism. European Proceedings of Social and Behavioural Science, 31, 986-994.

[3] Bob, P., Pec, O., \& Raboch, J. (2014). Dissociation in Schizophrenia and Borderline Personality Disorder. Neuropsychiatric Disease and Treatment, 487.

[4] Justo, A., Risso, A., Moskowitz, A., \& Gonzalez, A. (2018). Schizophrenia and Dissociation: Its Relationship with Severity, Self-Esteem and Awareness of Illness. Schizophrenia Research, 197, 170-175.

[5] Freud, S. (1952). Totem and Taboo. Some Points of Agreement Between the Mental Lives of Savages and Neurotics. New York, Norton.

[6] American Psychiatric Association. (2000). Diagnostic and Statistical Manual of Mental Disorders, (4th Ed., Text Revision). Washington, DC: American Psychiatric Association.

[7] Salokangas, R. K., Honkonen, T., \& Saarinen, S. (2003). Women Have Later Onset Than Men in Schizophrenia--But Only In Its Paranoid Form. Results of The DSP Project. European Psychiatry: The Journal Of The Association Of European Psychiatrists, 18(6), 274-281.

[8] Tudose, F., Tudose, C. \& Dobranici, L. (2011). Tratat De Psihopatologie Si Psihiatrie Pentru Psihologi. București: Editura Trei.

[9] Trifu S. (2019). Neuroendocrine Insights into Burnout Syndrome. Acta Endo (Buc) 2019; 15: 404-405.

[10] Freud, S. (1963). The Sexual Enlightenment of Children. London: Macmillan Publishing Company. 